\title{
Sympathetic skin response following single and combined sound and electrical stimuli in young healthy subjects
}

\author{
Agnieszka Wiertel-Krawczuk, Adam S. Hirschfeld, Juliusz Huber, Magdalena Wojtysiak, \\ Agnieszka Szymankiewicz-Szukała
}

Department of Pathophysiology of Locomotor Organs, Poznan University of Medical Sciences, Poland

\begin{abstract}
Introduction. Sympathetic skin response (SSR) is applied in evaluation of dysfunctions in autonomic nervous system. Among others, electrical and sound stimuli are most frequently used to evoke SSR.

Aim. The aim of this study was to determine if the bell ring stimulus with parameters different from standard sound stimulation evokes similar reactions in autonomic system as electrical stimulus with defined parameters. Material and methods. SSR parameters were recorded following simultaneous sound and electrical stimulation. Twenty young volunteers (aged $23 \pm 2.1$ years) were examined once with SSR and R-R interval variation (RRIV) tests in order to confirm lack of functional changes in autonomic nervous system.

Results. Values of mean amplitudes of SSR were always higher during recordings from upper limbs than the lower ones irrespective of the three types of applied stimuli. Mean values of latencies were comparable when SSR were induced with acoustic, electrical and both stimuli during recordings performed from upper and lower extremities. Bell ring stimulus influenced only mean values of SSR area recorded both from upper $(p \leqslant 0.011)$ and lower $(p \leqslant 0.023)$ extremities. Heart beats variability in RRIV recordings changed at $13.5 \%$ which is comparable to results obtained by other authors.

Conclusions. Results indicate that the application of different modalities stimuli evokes SSR with comparable parameters. Each of them can be used for objective evaluation of the sympathetic nervous system function. Both SSR and RRIV tests evaluating the function of two effector types should be applied for the diagnosis of the probable dysautonomia in patients who show unclear clinical symptoms.
\end{abstract}

Keywords: sympathetic skin response, acoustic stimulus, electrical stimulus, R-R interval variation, normative values, autonomic system.

\section{Introduction}

The clinical evaluation of autonomic system disorders can be difficult because of the unspecific symptoms [1]. Ascertaining of dysautonomia using accurate and non-invasive methods of functional diagnostic is crucial [2]. The results of sympathetic skin response SSR and the analysis of heart rate variability - RRIV functional examinations constitute the completion of its clinical diagnosis $[3,4]$. Among the many tests to assess the function of the autonomic nervous system, the above-mentioned two types of tests are the most commonly used to confirm dysautonomia. The reaction of two kinds of effectors following the autonomic nervous system activation allows evaluating its function precisely.

Examination of the sympathetic skin response is based on the temporary changes in the electrical skin resistance caused by the synchronous activation of the 
sweat glands. Applications of an unexpected external stimulus such as electrical (stimulation of median, tibial, peroneal or supraorbital nerves), physiological (sound, flash or touch) as well as emotional excitation evoke SSR [5-8]. Usually the electrical stimulus with $0.2 \mathrm{~ms}$ duration and $15-30 \mathrm{~mA}$ intensity is applied or the acoustic stimulus with the frequency of $100 \mathrm{~Hz}, 100 \mathrm{~ms}$ duration and $80 \mathrm{~dB}$ intensity via earphone biaural stimulation [9]. Considering the fact that sweat gland excitation can be the result from stimuli of different modality (e.g. emotional), the assessment of possible SSR parameters variability is interesting. Changes of SSR latency and amplitude are also not fully explained in the context of the application of the two stimuli simultaneously [8, $10]$, together with including the bell ring stimulation with different parameters than commonly accepted.

The heart rate variability depends on the phase and depth of breathing and it is controlled by vagal cholinergic impulsation which acting on the sino-atrial node slows the heart beats. During inspiration the parasympathetic activation is reduced. The opposite situation occurs in the expiratory phase. Deep breathing leads to changes in the autonomic system activity, thus increasing the heart rate variability $[1,2]$.

\section{Aim}

The aim of this study is to evaluate possible changes in SSR parameters by ascertaining their reference values in young, healthy volunteers aged from 19 to 27 , when two types of stimuli such us bell ring (with parameters different than those applied in bi-aural with headphones) and electrical are used separately or simultaneously. The hypothesis has been put forward that every type of stimuli evokes SSR with the similar, repeatable parameters. Autonomic R-R interval variation (RRIV) examination is used in this study to confirm no pathology in cardiovagal function of the subjects.

\section{Material and Methods}

\section{Subjects}

The project was carried out from March to September, 2014. The final group included twenty young healthy volunteers who were examined once. There were 10 women aged from 22 to 27 ( $24 \pm 2$ years on average),
$1.67 \pm 0.09 \mathrm{~m}$ in height and 10 men aged from 19 to 26 (22 \pm 2 years on average) $1.8 \pm 0.06 \mathrm{~m}$ in height. The inclusion criteria were as follows: young subjects, who presented a general good health condition, having similar anthropometric properties, reported no neurological disorders, no autonomic diseases basing on the medical history from general practitioner. All subjects denied previous alcohol or drugs abuse. All participants gave written informed consent prior to the study. Ethical considerations were in agreement with the Helsinki Declaration. Demographical data of the examined subjects $(N=20)$ are presented in Table 1.

\section{Instruments}

The subjects were examined in a supine position in an air-conditioned room where the temperature was kept at $23^{\circ} \mathrm{C}$ on average. They were given 15 minutes of relaxation prior to the applied tests. The regime of quiet was rigorously kept. The same team of investigators performed all examinations. Four-channel KeyPoint system (Medtronic A/S Skovlunde Denmark) was used for recordings. The upper filter was set on $2 \mathrm{kHz}$, the lower one on $0.5 \mathrm{~Hz}$. During recordings of SSR and RRIV the time base was set on $1 \mathrm{~s} / \mathrm{D}$ and $200 \mathrm{~ms} / \mathrm{D}$ and amplifications from 0.5 to $1 \mathrm{mV}$, respectively. RRIV was recorded for $60 \mathrm{~s}$.

Surface bipolar stimulating electrode was placed over the right median nerve unilaterally at the wrist. Rectangular electrical "train" stimuli at the intensity of $10 \mathrm{~mA}$, duration of $0.1 \mathrm{~ms}$ and frequency at $3 \mathrm{~Hz}$ in SSR studies were used (Figure 1). The impendency between the skin and the surface electrode did not exceed $5 \mathrm{k} \Omega$. In order to obtain the lowest impendency, the skin was cleared with special paste which did not contain alcohol as the possible factor influencing the secretion of sweat glands. The surface $\mathrm{AgCl}$ adhesive disposable electrodes (recording surface $7 \times 4 \mathrm{~mm}$ ) were covered with a small amount of the isotonic gel to diminish the resistance between electrode plates and the skin. The active recording electrodes were placed in the middle of palms and soles at the areas between $2^{\text {nd }}$ and $3^{\text {rd }}$ metacarpus and metatarsus, respectively. Reference electrodes were placed centrally on the dorsal aspects of hands and feet. Ground electrodes were placed unilaterally at the wrist and ankle proximately

Table 1. Demographic data on examined subjects (mean values $\pm S D$ )

\begin{tabular}{ccccc}
\hline Control group $(\mathrm{N}=20)$ & Age $($ years $)$ & Height $(\mathrm{m})$ & Weight $(\mathrm{kg})$ & $\mathrm{BMl}$ \\
\hline$\hat{\sigma}=10 q=10$ & $23 \pm 2.1$ & $1.74 \pm 0.1$ & $64.5 \pm 10.4$ & $21.28 \pm 1.7$ \\
\hline
\end{tabular}




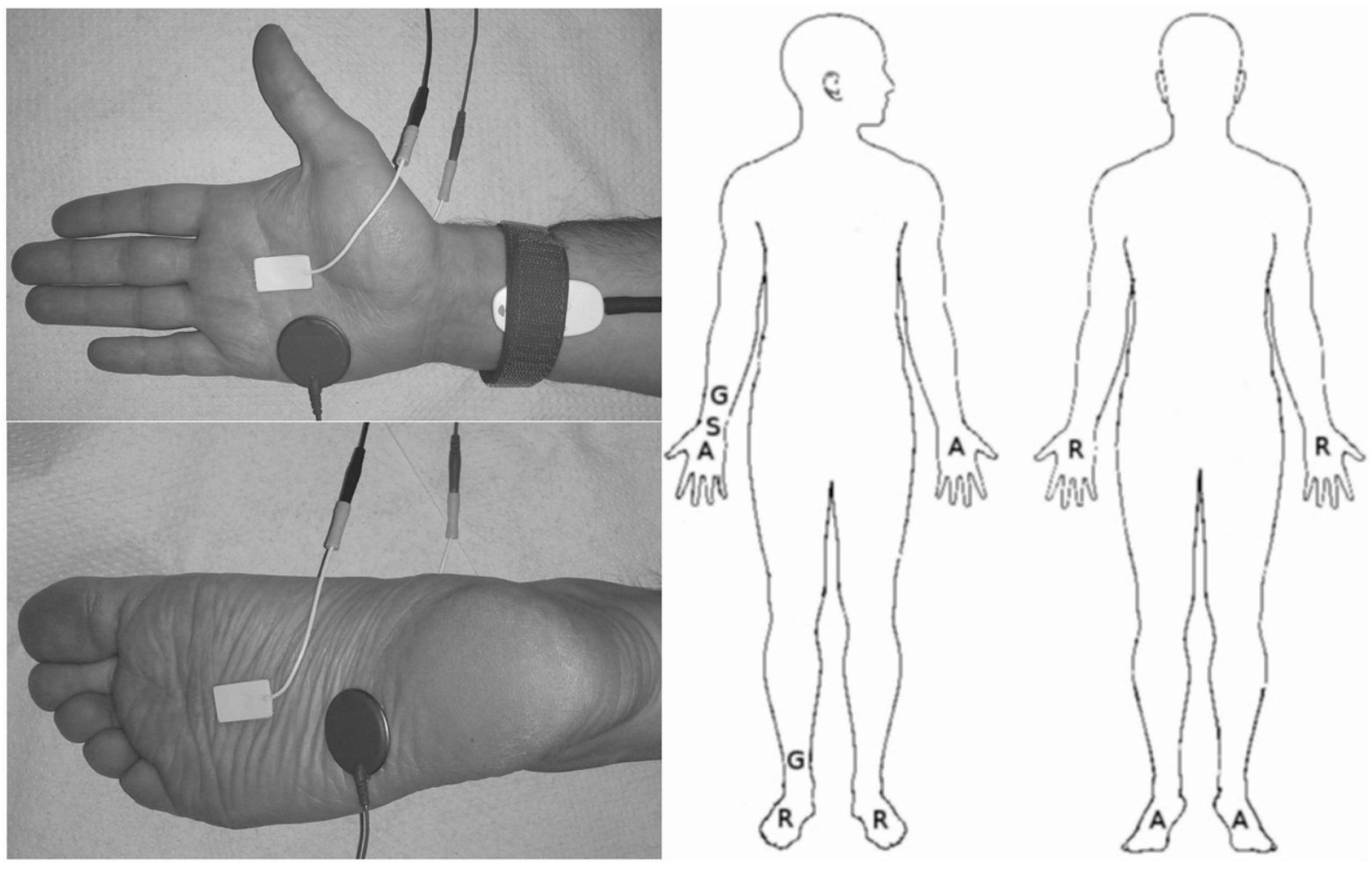

Figure 1. Scheme of the electrodes locations used in SSR studies. S - stimulating electrode, A -active recording electrode, $R$ - reference recording electrode, G-ground electrode

to the recording electrodes according to descriptions of Claus and Schondorf [6] and Lee and DeLisa [11].

Three attempts for each session of SSR recordings from upper and lower extremities were conducted. In order to avoid the possible habituation, the irregular interval between each trial was applied. Latencies, amplitudes, areas and configuration (number of phases) of SSR were analysed. The latency was ascertained from the stimulus artefact following the first negative deflexion from baseline, it means to the onset of potential (in seconds). The amplitude was measured from the peak of the negative to the positive component (in millivolts).

The bell ring stimulus was also used to evoke SSR. No headphones were used. Every time the sound stimulus was applied from the same distance of the subject's head (approximately at $30 \mathrm{~cm}$ ) and, which is important, stimulus application was simultaneously triggered with the onset of the recording indicated by marker. This eliminated the possible delay in reaction of sweat glands to stimulus, which might have determined the recordings latency variability. The frequency was kept at 3-4 $\mathrm{Hz}$ with the sound maximal intensity at $85 \mathrm{~dB}$ ( $64 \mathrm{~dB}$ on average). The acoustic stimulus was delivered for $3 \mathrm{~s}$. The third way of evoking SSR was a combined bell-electrical stimulus induced in the same way as the one described separately. The bell ring and electrical stimuli were delivered exactly at the same moment and they triggered the onset of recording.

SSR responses with the shortest latencies were analysed. If the repeated stimulation brought no responses, the difference in latencies of recorded responses on both sides was greater than $50 \%$ or the results exceeded mean \pm 2 SD values they were not included in the final analysis $(\mathrm{N}=4)$.

The analysis of the R-R interval variation was performed with an active electrode placed on the $4^{\text {th }}$ left intercostal space in the parasternal line and the reference electrode was placed in the right first intercostal space of the mammillary line. The ground electrode was located on sternum [12]. RRIV analysis included one minute recording during the normal (individual rhythm) and deep, regular breath (six breaths per minute) [13]. The percentage of changes in variability of R-R intervals then was assessed, as well as the frequency of heart beats per minute on both stages of examination. The improper result was ascertained as exceeding mean \pm 2 SD values or the characteristic invariable (homogenic) recording was observed.

\section{Statistical analysis}

SSR parameters were described as ranges, mean values and their standard deviations. RRIV measure- 
ments results were expressed as mean percentages of changes in R-R intervals basing on equation:

$$
\%=\frac{\text { max.value }- \text { min.value }}{\text { mean value }}
$$

The normality distribution test for SSR parameters was performed with Shapiro-Wilk test. The homogeneity of variances recorded on both sides and both sexes was tested with Mann-Whitney test. Differences in parameters of SSR induced with three types of stimuli were verified with ANOVA Friedmann test. The level of statistical significance was accepted at $p \leqslant 0.05$. All statistical analyses were performed using Statistica PL software version 9.0 (by StatSoft).

\section{Results}

During preliminary analysis the statistically significant differences at $p<0.05$ between parameters of SSR recordings performed on both sides were not found, hence the results obtained in 20 volunteers were considered together as $N=40$. The data regarding the obtained parameters in SSR recordings evoked with three types of stimuli are presented in Table 2 .

Examples of SSR recordings are presented in Figure 2. Mean values of SSR amplitudes (mainly biphasic, with the first negative inflection) were always higher when recorded from the upper extremities, than from the lower ones, irrespective of the type of the applied stimulus. The mean values of latencies were also comparable when recorded from upper and lower extremities. It means the type of stimulus not change their values (Table 2).

The results of Friedmann's test presented in Table 3 show that the type of stimulus influenced only mean values of the SSR area parameter recorded both in upper $(p \leqslant 0.011)$ and lower $(p \leqslant 0.023)$ extremities.

The relation between amplitude and area parameters can be clearly observed in histograms shown in Figure 3. The SSR area parameter was significantly smaller when the bell ring stimulus was applied than with the application of electrical and electrical-sound combined stimuli. The reduction of SSR area was caused by lower value of its amplitude during bell ring

Table 2. Data on results from SSR examination during recordings from upper and lower extremities following all three applied types of stimuli. Ranges, means and standard deviations are shown

\begin{tabular}{lcc}
\hline \multicolumn{1}{c}{ Parameters } & $\begin{array}{c}\text { Upper extremities } \\
\text { recordings } \\
(\mathrm{N}=40)\end{array}$ & $\begin{array}{c}\text { Lower extremities } \\
\text { recordings } \\
(\mathrm{N}=40)\end{array}$ \\
\hline Amplitude & \multicolumn{2}{c}{ Electrical stimulation } \\
(mV) & $0.19-2.36$ & $0.12-2.00$ \\
\hline Latency & $1.13 \pm 0.58$ & $0.73 \pm 0.52$ \\
(s) & $1.31-1.89$ & $1.75-2.72$ \\
\hline Area & $1.58 \pm 0.16$ & $2.13 \pm 0.21$ \\
(mV/s) & $0.22-4.18$ & $0.11-3.10$ \\
\hline & $1.38 \pm 0.81$ & $0.87 \pm 0.65$ \\
\hline Amplitude & \multicolumn{2}{c}{ Sound stimulation } \\
(mV) & $0.12-3.40$ & $0.14-3.01$ \\
\hline Latency & $0.99 \pm 0.89$ & $0.56 \pm 0.51$ \\
\hline (s) & $1.15-1.94$ & $1.27-2.64$ \\
\hline Area & $1.56 \pm 0.23$ & $2.09 \pm 0.28$ \\
(mV/s) & $0.19-4.72$ & $0.13-3.61$ \\
\hline & $1.14 \pm 1.08$ & $0.66 \pm 0.68$ \\
\hline Amplitude & Electrical and sound stimulation \\
\hline (mV) & $0.20-2.24$ & $0.09-3.06$ \\
\hline Latency & $1.15 \pm 0.60$ & $0.71 \pm 0.58$ \\
\hline (s) & $1.18-1.80$ & $1.65-2.61$ \\
\hline Area & $1.51 \pm 0.14$ & $2.09 \pm 0.24$ \\
(mV/s) & $0.22-5.32$ & $0.09-3.83$ \\
\hline & $1.44 \pm 0.92$ & $0.84 \pm 0.71$ \\
\hline
\end{tabular}
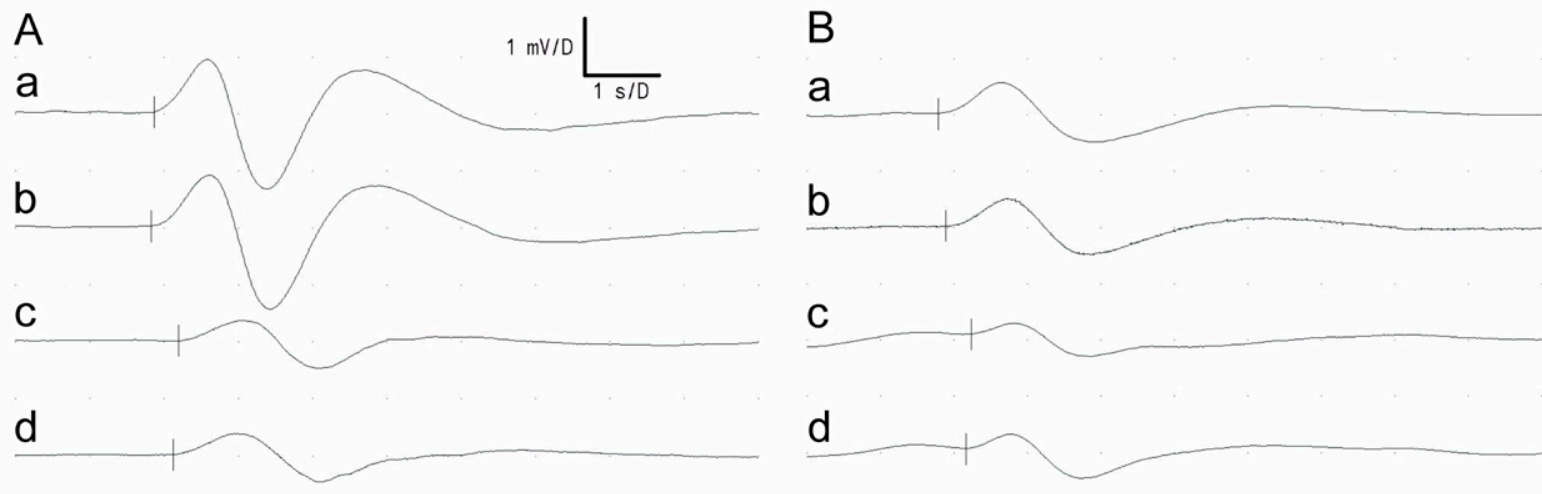

Figure 2. Examples of sympathetic skin responses recorded in two of healthy volunteers when evoked with (A) electrical stimulus and (B) sound stimulus. Recordings were acquired from right and left upper $(a, b)$ and lower extremities $(c, d)$ 
Table 3. Differences in parameters of SSR evoked potentials with three types of stimuli. Asterisks $\left(^{*}\right)$ indicate the statistically significant differences at $p \leqslant 0.05$

\begin{tabular}{lcc}
\hline \multirow{2}{*}{ Parameter } & \multicolumn{2}{c}{$p$} \\
\cline { 2 - 3 } & Upper extremities & Lower extremities \\
\hline Amplitude $(\mathrm{mV})$ & 0.062 & 0.081 \\
\hline Latency $(\mathrm{s})$ & 0.105 & 0.495 \\
\hline Area $(\mathrm{mV} / \mathrm{s})$ & $0.011^{*}$ & $0.023^{*}$ \\
\hline
\end{tabular}

Table 4. Comparison of mean values of percentage changes in RRIV tests obtained in this and other authors studies

\begin{tabular}{lcc}
\hline & This study & Other studies \\
\hline Normal breathing & 24.45 & $18.91 ; 18.62$ \\
\hline Deep breathing & 37.95 & $31.01 ; 31.42$ \\
\hline $\begin{array}{l}\text { Normal-deep breathing } \\
\text { difference }\end{array}$ & 13.5 & $12.11 ; 13.72$ \\
\hline${ }^{1}$ Shen
\end{tabular}

${ }^{1}$ Shahani et al. 1990, ${ }^{2}$ Ozgocmen et al. 2006
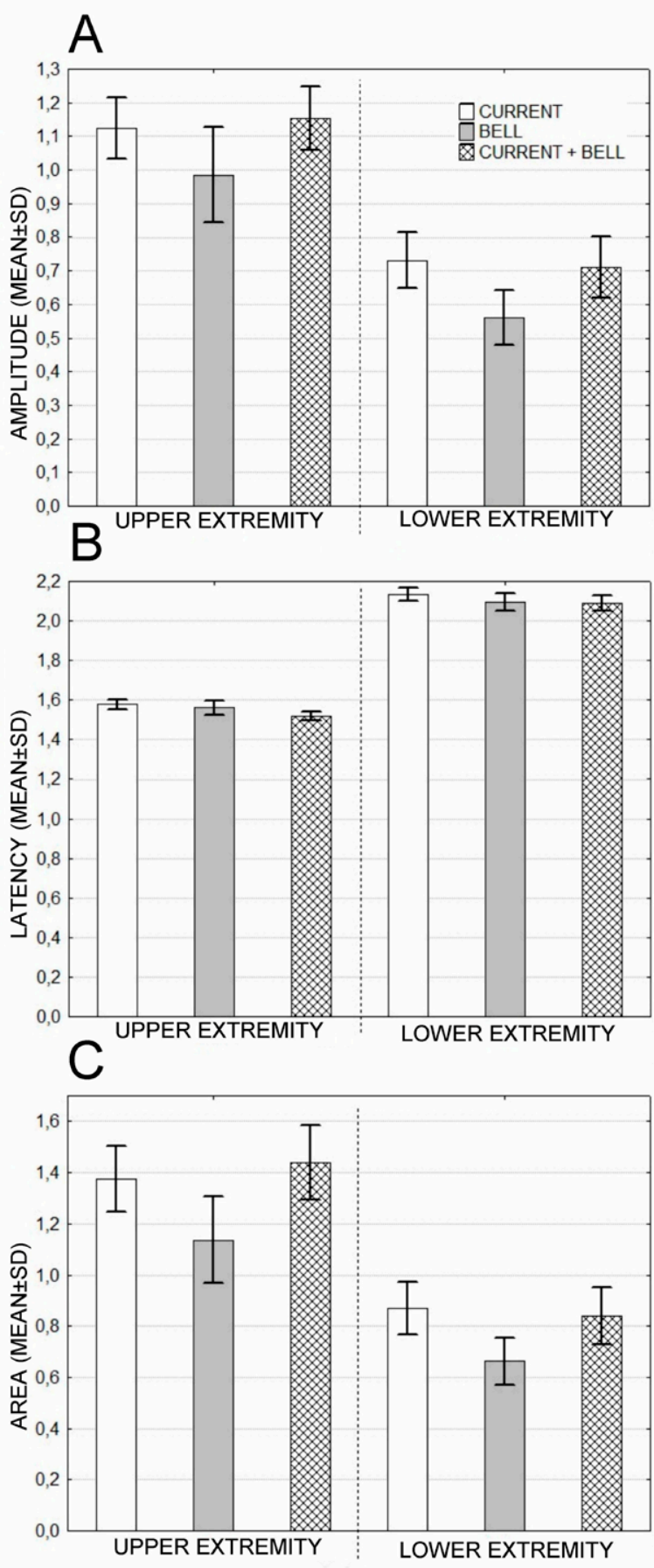

Figure 3. Histograms showing distribution of mean values and standard deviations with reference to parameters of amplitudes (A), latencies (B) and areas (C) of recorded SSR from upper and lower extremities when evoked with three types of stimuli. Note similar latencies but variability of amplitudes influences the area parameter in sound stimulations 

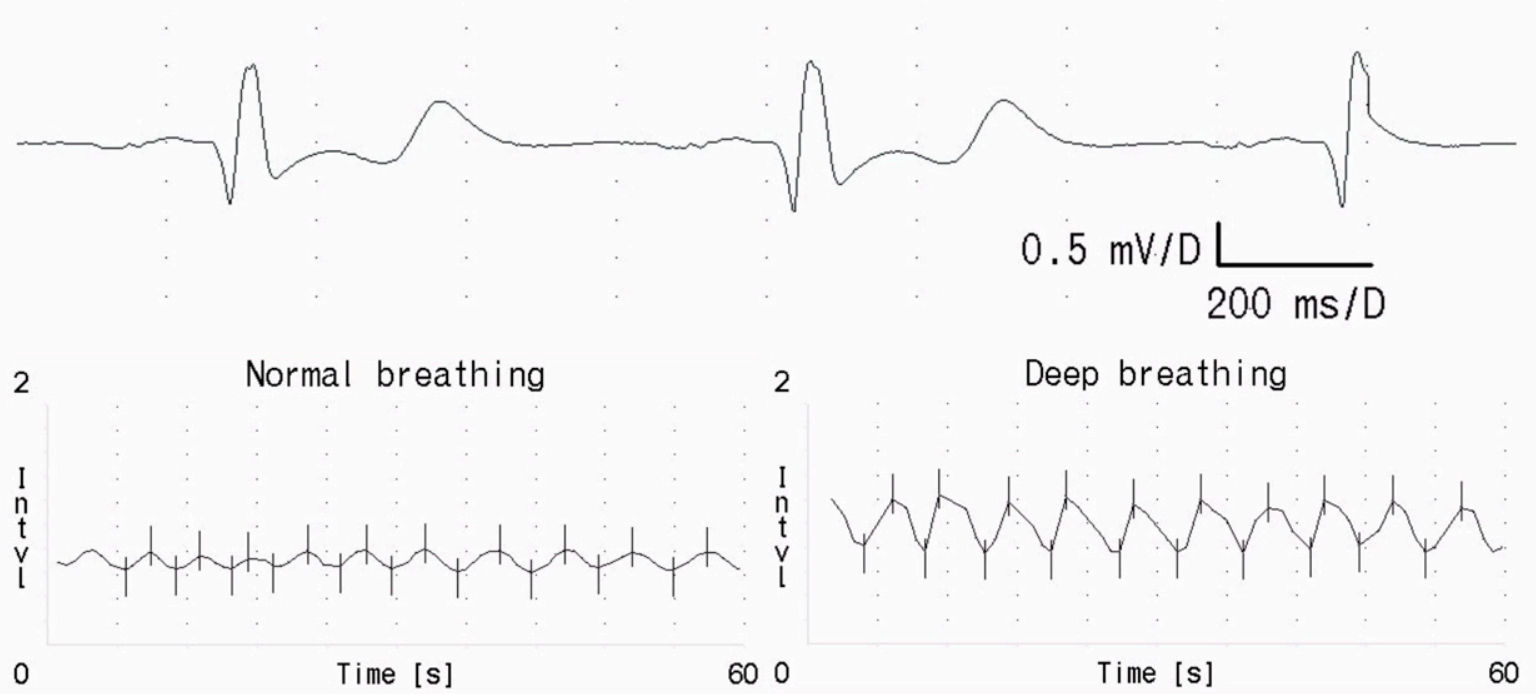

$2 \quad$ Deep breathing

Figure 4. Examples of RRIV recordings performed in one of examined volunteers during normal and deep breathing

stimulation when recorded from both upper and lower extremities. The standard deviation for the SSR amplitude recorded during three types of stimulation was close to the range $0.5-0.6 \mathrm{mV}$. Thus, it can be assumed that bell ring stimulus evokes the response with lower values of amplitude which can be probably explained by weaker excitation of the sympathetic system than the one with the electrical stimulus.

Examples of proper RRIV recordings during normal and deep breathing are presented in Figure 4 while their principles are presented in Table 4. During deep breathing the increase in heart beats was predominantly observed (in $70 \%$ of examined persons). The percentage difference of heart beats variability changed by $13.5 \%$ which was parallel with the RRIV amplitude increase during the deep breathing.

\section{Discussion}

One of the aims of this paper was the analysis of the influence of the different from standard sound and electrical stimuli on the parameters of evoked SSR. Similar studies have not been performed according to the data available from literature. Only the work of Elie et al. [9] describes a similar combination of the two types of stimulation to induce SSR. However, they have used different values of the stimulus than in our research. Bursts of bi-aural stimuli with intensity at 85-105 dB and electrical stimulation at 0.85, 1 and 1.15 times threshold of the median nerve excitability were used, evoking responses with similar values as in our research. Using of electrical stimulus with intensity not exceeding $10 \mathrm{~mA}$ was also intentional in our tests. The stimulus with such values eliminates the possible modulation of the evoked response to stimulation of endogenous origin, such as pain, movement or sudden breath. Taking into account the comparison of results, obtained SSR recordings with electrical, other defined as bell ring and the combination of both stimuli had similar parameters. Mean values of SSR latencies evoked with defined electrical stimulus in our study are comparable to the results obtained by other authors [5, 14-16], which is presented in Table 5. Shahani at al. [13] and Levy et al. [17] described results of SSR evoked with undefined stimulus taking the origin from deep breathing. They recorded parameters of latencies similar to the ones observed in our sample when defined bell ring stimulus was applied.

During SSR recordings, the moment of defined bell ring stimulus applied simultaneously to the recording onset is methodologically crucial for obtaining the responses with similar latencies. This condition was rigorously kept during SSR tests performed in this study. The differences of latencies values which ranged at $\pm 0.2 \mathrm{~s}$ for recordings obtained from upper and lower extremities were not significant. On the other hand, the latencies of SSR responses recorded following excitation with sound stimulus and combined electrical-sound stimuli were very close to those evoked by electrical stimulus only. The centripetal conduction time is depended on the stimulus type, however, it constitutes only $5 \%$ of SSR latency. This phe- 
Table 5. Comparison of mean values of latencies (in seconds) from SSR recordings evoked with electrical stimulus during this study to latencies of SSR in studies of other authors

\begin{tabular}{lcc}
\hline $\begin{array}{c}\text { Recorded } \\
\text { extremities }\end{array}$ & This study & Studies of other authors \\
\hline Upper & $1.58 \pm 0.16$ & $1.391 ; 1.322 ; 1.433 ; 1.214 ; 1.55$ \\
\hline Lower & $2.13 \pm 0.22$ & $1.881 ; 1.722 ; 2.233 ; 1.864 ; 2.25$ \\
\hline${ }^{1}$ Shahani et al. 1984 & \\
${ }^{2}$ Zakrzewska-Pniewska et al. 1998 & \\
${ }^{3}$ Cariga et al. 2002 \\
${ }^{4}$ Ozgocmen et al. 2006 \\
${ }^{5}$ tabuz-Roszak et al. 2009
\end{tabular}

nomenon does not influence the final result of latency value. The comparison of our data on SSR latency with the results of other authors is not possible because of any particular data on this problem except for the work of Elie and Guiheneuc [9] who used the biaural tone burst for stimulation. They also did not observe changes in SRR latencies evoked with bimodal and electrical stimulation.

Similarly to the studies of Shahani et al. [5], SSR recordings from upper extremities were with higher amplitudes than those recorded from lower extremities during the application of electrical stimulation. Moreover, in our study a similar phenomenon was observed for a combined type of stimulation. During the application of bell ring the mean value of amplitude was lower both for upper and lower extremities than in other types of stimulations (Figure 3 ). The value of bell ring at $80 \mathrm{~dB}$ (40-50 dB above the hearing threshold) evokes SSR with optimal amplitude (> $180 \mu \mathrm{V}$ recorded from palm, $>160 \mu \mathrm{V}$ recorded from foot). The bell ring stimulus applied in our study beside other parameters and different technique, evoked SSR with similar latency values as reported by Kucera et al. [18] but the amplitude was lower. Greater variability of amplitude and area parameters can be also influenced by the habituation phenomenon $[1,5,6,18]$. It can be concluded that latency parameter is more objective in SSR recordings for the evaluation of autonomic nervous system function than amplitude. There were not changes in values of this parameter in the studies of other authors [5, 19-22] who stimulated nerves with intensity in the range from 10 to $60 \mathrm{~mA}$. Stimulation of nerves other than median (tibial, peroneal and supraorbital nerves) did not influence SSR parameters $[14,23,24]$.

Gender differences were not observed during the analysis of SSR parameters in our studies. Basing on the descriptions of other authors, height and body mass did not influence SSR responses $[6,17]$. However, changes in their parameters in $50 \%$ of the people after 60 were observed [18, 25]. These data cannot be verified by our studies because of our sample homogeneity. The lack of SSR recording can be a sign of dysautonomia as well as their unilateral recording or absolute value of latency more than \pm 2 SD. Routinely applied both types of stimuli (sound or electrical) during SSR evaluation may reveal the level of pathology origin with respect to the afferent routes of impulses transmission.

Mean results obtained from RRIV recordings are comparable to those obtained by other authors (Table 5). R-R variability during the deep breathing and the heart beat acceleration were observed in 18 out of 20 of the examined volunteers. The diagnostic sensitivity of this test might have been proved by no false results during the examination of young, healthy volunteers. Repeatability, short duration (2 minutes) and non-invasive nature of this study are its advantages.

Attempts are made to use SSR and RRIV tests in confirmation of spinal muscular atrophy, progressive autonomic failure, fibromyalgia, uraemia, diabetes, polyneuropathies, carpal tunnel syndrome, disturbances in patients with Parkinson's diseases or epilepsy diagnoses [13, 15, 16, 19, 21, 22, 26]. No SSR responses during the application of both types of stimuli (sound and electrical) should be considered in confirmation of dysautonomia coexistence.

Similar studies comparing results from population of young and elder people would profit on the topic of using electrical and sound defined stimuli as triggers of SSR. Several neurological diseases affect rather older people and the parameters of the vegetative responses may change with age.

\section{Conclusion}

In conclusion, the various modalities of stimuli used in our studies evoke SSR with comparable values. However, in our opinion, the most objective parameter is a stable value of the SSR latency, regardless of the type of applied stimuli. Using of both electrical and sound stimuli is very important because it allows differentiation of abnormal SSR responses associated with the possible peripheral neuropathy. Compilation of SSR studies using different modalities of stimuli, as well as clinical and RRIV examination may influence the precision of dysautonomia diagnosis.

\section{Acknowledgements}

\section{Conflict of interest statement}

The authors declare no conflict of interest. 


\section{Funding sources}

There are no sources of funding to declare.

\section{References}

1. Ravits JM. AAEM minimonograph \#48. autonomic nervous system testing. Muscle and Nerve. 1997;20:919937.

2. Zygmunt A, Stanczyk J. Methods of evaluation of autonomic nervous system function. Arch Med Sci. 2010;6:1118.

3. Baba M, Watahiki Y, Matsunga M, Takebe K. Sympathetic skin response in healthy man. Electromyogr Clin Neurophysiol. 1988;28;277-283.

4. Baron R, Ewing DJ. Heart rate variability. The International Federation of Clinical Neurophysiology. Electroencephalogr Clin Neurophysiol Suppl. 1999;52:283-286.

5. Shahani BT, Halperin JJ, Boulu P, Cohen J. Sympathetic skin response a method of assessing unmyelinated axon dysfunction in peripheral neuropathies. J Neurol Neurosurg Psychiatry. 1984;47:536-542.

6. Claus D, Schondorf R. Sympathetic skin response. In Recommendations for the practice of clinical neurophysiology. guidelines of the International Federation of Clinical Neurophysiology. $2^{\text {nd }}$ ed. Edited by Deuschl G, Eisen A. Amsterdam. Elsevier Science BV 1999.

7. Mathias CJ. Autonomic diseases. clinical features and laboratory evaluation. J Neurol Neurosurg Psychiatry. 2003;74:(Suppl 3);iii31-iii41.

8. Vetrugno R, Liguori R, Cortelli P, Montagna P. Sympathetic skin response. basic mechanisms and clinical applications. Clin Auton Res. 2003;1:256-270.

9. Elie, B, Guiheneuc, P. Sympathetic skin response. normal results in different experimental conditions. Electroencephalogr Clin Neurophysiol. 1990;76;258-267.

10. Satchell PM, Seers CP. Evoked skin sympathetic nerve responses in man. J Neurol Neurosurg Psychiatry. 1987;50:1015-1021.

11. Lee JH, DeLisa JA. Sympathetic Skin Response. In Manual of nerve conduction study and surface anatomy for needle electromyography. $4^{\text {th }}$ ed. Philadelphia. Lippincot Williams\&Wilkins, 2005.

12. Yoshimura T, Yonezawa $Y$, Maki H, Ogawa H, Ninomiya I, Morton Caldwell W. An ECG electrode-mounted heart rate, respiratory rhythm, posture and behavior recording system. Med Biol Soc. 2004;4:2373-2374.

13. Shahani BT, Day TJ, Cros D, Khalil N, Kneebone ChS. RR Interval Variation and the Sympathetic Skin Response in the Assessment of Autonomic Function in Peripheral Neurophaty. Arch Neurol. 1990;47:659-664.

14. Zakrzewska-Pniewska B, Przybyłowski T, Byśkiniewicz K, Kostera-Pruszczyk A, Droszcz W, Emeryk-Szajewska B. Sympathetic skin response in obstructive sleep apnea syndrome. Acta Neurobiol Exp. 1998;58:113-121.

15. Cariga P, Catley M, Mathias CJ, Savic G, Frankel HL, Ellaway $\mathrm{PH}$. Organisation of the sympathetic skin response in spinal cord injury. J Neurol Neurosurg Psychiatry. 2002;72:356-360.
16. Ozgocmen S, Yoldas T, Yigiter R, Kaya A, Ardicoglu O. $R-R$ interval variation and sympathetic skin response in fibromyalgia. Arch Med Res. 2006;37:630-634.

17. Levy DM, Reid G, Rowley DA, Abraham RR. Quantitative measures of sympathetic skin response in diabetes. relation to sudomotor and neurological function. J Neurol Neurosurg Psychiatry. 1992;55:902-908.

18. Kucera P, Goldenberg Z, Kurca E. Sympathetic skin response. review of the method and its clinical use. Bratisl Lek Listy. 2004;105:108-116.

19. Zakrzewska-Pniewska B, Jędras M. Is puritus in chronic uremic patients related to pheripheral somatic and autonomic neurophaty? Study by R-R interval variation test (RRIV) and by sympathetic skin response (SSR). Neurophysiol Clin. 2001;31:181-193.

20. Chroni E, Argyriou AA, Polychronopoulos P, Sirrou V. The effect of stimulation technique on sympathetic skin responses in healthy subjects. Clin Auton Res. 2006;16:396-400.

21. Łabuz-Roszak B, Pierzchała K. Assessment of autonomic nervous system in patients with epilepsy in the interictal state. A pilot study. Neurol Neurochir Pol. 2009;43:330336.

22. Deniz O, Aygül R, Kotan D, Ozdemir G, Odabaş FO, Kaya $M D$, Ulvi $H$. The effect of local corticosteroid injection on F-wave conduction velocity and sympathetic skin response in carpal tunnel syndrome. Rheumatol Int. 2012;32:1285-1290.

23. Kim CT, Chun SI. Sympathetic skin response recorded by 4 channel recording system. Yonsei Med J. 1994;35:149154.

24. Choi BO, Bang OY, Sohn YH, Sunwoo IN. Sympathetic skin response and cardiovascular autonomic function tests in Parkinson's disease. Yonsei Med J. 1998;39:439445.

25. Drory VE, Korczyn AD. Symphatetic skin response. Age effect. Neurology. 1993;43:1818-1820.

26. Zakrzewska-Pniewska B, Jamrozik Z. Are electrophysiological autonomic tests useful in the assessment of dysautonomia in Parkinson's disease? Parkinsonism Relat Disord. 2003;9:179-183.

Acceptance for editing: 2016-06-29 Acceptance for publication: 2016-06-30

Correspondence address: Prof. Juliusz Huber MSc PhD Department of Pathophysiology of Locomotor Organs Poznan University of Medical Sciences 135/147 28 Czerwca 1956 St, 61-545, Poznań, Poland phone/fax: +48618310230 email: zpnr@wp.pl 